be it noted, not for food or health purposes but for commercial money-making only. Still pursuing this self-interested propaganda, the great commercial interests concerned described this process as an "improvement" and the chemicals used as "improvers," and it is here that I would like to enter a plea for the abolition of this unnecessary interference with our food and for the accurate use of English words, especially in scientific journals.

Hitler gave us many examples of how to disguise unpleasant truths by substituting mild-sounding words, as when he described his cold-blooded murders as "liquidation"; and when commercial firms adulterate our food with poisons which have caused madness and death in numerous dogs let us call it quite plainly "adulteration" and not "improvement."-I am, etc.,

Slough, Bucks.

H. TUdor EDMunds.

\section{Sterilization of Syringes}

SIR,-The evidence in favour of boiling as opposed to fluid antiseptics for the sterilization of syringes is overwhelming and is quite untouched by the anonymous impressions described by "Ex-R.A.M.C." (Dec. 14, 1946, p. 920). Rather in the spirit of offering testimony against a method that has already been found guilty but not yet condemned to die, the salient points may be stated as follows.

For many years past in venereal disease clinics there has been a small but definite incidence of jaundice, but this condition became more and more common in the Services after 1941, reaching a very high rate in the years immediately following. ${ }^{1}$ Its nature and mode of infection were at that time unknown, but it was in many quarters considered as primarily due to arsenic. In 1943 Bigger $^{2}$ showed that the existing methods of syringe. sterilization by means of spirit were in fact far from effective, and he and $\mathrm{MacCallum}^{3}$ independently suggested that this faulty sterilization might be in part responsible for the jaundice. The following year, Salaman et al. $^{4}$ showed that if the syringes were autoclaved and strict antiseptic precautions adopted, then this disease could be practically eliminated from a clinic. (This was later amply confirmed by Laird, ${ }^{5}$ who employed boiling.) Boiling of syringes became compulsory for intravenous work, and the subsequent drop in the incidence of jaundice in a department where previously the rate had been high has been described. ${ }^{6}$ While the policy was approved, it was not as vigorously pursued in respect of intramuscular injections, not only on account of a relative shortage of syringes, but also as it was considered that syringes were not likely to become contaminated during routine injections by this method as long as care was taken always to boil the needles.

Before syringe transmission was incriminated in respect of intravenous injections there had been several published cases where jaundice had followed administration by the intramuscular route. Hartfall et al. ${ }^{7}$ (1937) reported hepatitis following the use of gold salts; Kulchar et al. ${ }^{8}$ described 120 cases following bismuth therapy; and penicillin injections were themselves held responsible in 47 cases by Howells et al. ${ }^{9}$ in 1946 ; and 26 others were more recently collected by Hughes. ${ }^{10}$ By the present time most venereologists can recall seeing one or several such cases. And now Hughes ${ }^{11}$ has shown that with the intramuscular technique syringe contamination is far from infrequent, but there seems to be a little reluctance in accepting the obvious implications of this modern version of the asepsis-antisepsis controversy.

The only point at which there is agreement with " $\mathrm{Ex}$ R.A.M.C." is when he writes: "It is hard to see... why an injection of penicillin would be more likely to contaminate a syringe than one of T.A.B., tetanus toxoid, or any of the other routine injections."-I am, etc.,

REFERENCES

1 Beattie, J., and Marshall, J., British Medical Journal, 1944, 1, 547.

2 Lancet, 1943, 1, 457

3 Brit. J. vener. Dis., 1943, 19, 63.

4 Lancet, 1944, 2, 7

5 Brit. J. vener. Dis., 1946, 22, 29

6 Willcox, R. R., J. R.A.M.C., 1946, 87, 51

7 Lancet, $1937,2,838$.

8 J. Amer. med. Ass., 1942, 120, 343.

9 Lancet, 1946, 1, 51.

10 British Medical Journal, 1946, 2, 685.

11 J. R.A.M.C., 1946, 87, 156.

\section{Man in Relation to His Environment}

SIR,-With reference to the letter on "Man in Relation to his Environment," by Dr. Frank Marsh (Nov. 9, p. 710), and the report of the British-Swiss Medical Conference (Sept. 28, p. 471), perhaps the experiences and conclusions of one who has lived for very many years in hot climates may be of interest. That experience has been a very long and varied one, in the hot back blocks of New South Wales, thirty years in India and Assam, three years in Mesopotamia, and a considerable time in South America. Five years at sea have given him an insight into ships' engine-rooms and stokeholds.

In studying the question of ventilation of spaces, rooms, buildings, and the effects on the human body, three factors must be constantly borne in mind: temperature, saturation, and movement of the air. Of these temperature is by far the least important. The human body can adapt itself to very large variations of temperature provided the other two factors are favourable. Cold, if the air is still and dry, as in Switzerland, is hardly felt. In a blizzard death will occur rapidly if there is no protection. Very high temperatures can be borne if the air is dry and moving. In regulating the loss of heat from the body the skin surface is in man the most important factor. The experiment has been tried with a man exposed to a vitiated atmosphere of keeping the body in that atmosphere and allowing the head to be in the air through a rubber dam. Under these circumstances there is little improvement in his sensations. Reverse the process, body in fresh air, head still in the bad atmosphere, and relief is rapid. A place is spoken of as bracing when the air there is dry and moving, relaxing when the opposite conditions prevail, and this irrespective of the temperature. The Iraki deserts are bracing if the cardinal conditions are observed: keep away from water, keep away from trees, and keep away from buildings and streets. When new units came to Mesopotamia, the tendency was to camp in the shady date groves along the banks of the rivers. Part of the duties of the writer was to chase them out of this into the open desert. He was met with strong expostulations, and it had to be explained why they would keep fitter in a dry and moving air in contradistinction to a still and moist one.

In all his residence in hot climates the writer has never seen or heard of an authentic case of sunstroke, insolation, or collapse through direct action of the sun's rays, though heat stroke and sunstroke are commonly confounded. Instances may be cited which bear out what has been said above. At one time in Bagdad during the 1914-18 war there were a very large number of cases of heat stroke with a very high mortality. Sir William Willcox came out to investigate. He asked how the cases were being treated and was shown a beautifully cool underground cellar such as is common in Iraki houses. There the cases were taken and splashed and bathed with cold water. What could be better than to treat such cases in the cool cellar? But Sir William thought otherwise. He said take them out into the open with improvised shade where there is a breeze, and then use your cold water and electric fans if available. The cases began to recover. In the cellar the temperature was low but the air was still and damp from the breathing of the staff and the water used. Again, in the attack on the Malakand, troops had to be sent in a forced march from Durgai. Capt. Wooley, I.M.S., in medical charge, related that while the men marched through the heat of the day they were perfectly fit. During the much cooler night, when they passed through a deep, rocky gorge where there was little perflation of air, the men went down like ninepins.

One very important point must be remembered: In a dry, hot, moving air the loss of water from the body through invisible perspiration is very large, and large quantities of salt are washed out of the blood-it may be with serious results. In the stokehold this is frequently seen as "fireman's cramp." Give such a sufferer a long drink of salt and water, which he laps down with the greatest gusto, and his cramps rapidly disappear. Intravenous injections of hypertonic saline have been used as an aid to the treatment of heat stroke. Diet in hot climates requires consideration. In cold climates a large number of calories are used in keeping up the body heat. The amount eaten is largely a matter of habit and those coming to the Tropics are inclined to eat as much as they did in a cooler clime. Another point which affects health in the Tropics 
is housing. Masonry houses must be of good size, with large and airy rooms and good verandas. Most European houses conform to this standard. It is otherwise with most of the Indian masonry dwellings. The rooms tend to be cellular and ill-ventilated, and in many cases the houses are too small.I am, etc.,

Taynuilt, Argyll.

P. F. Chapman

\section{Unemployed Specialists}

SIR,-Hospitals all over the country are being asked to consider the employment of full-time specialists at salaries of $£ 1,000$ per annum, and the Minister of Health has intimated that the Treasury will be willing to meet the cost of these salaries if the hospitals are unable to do so from their funds. Several points arise from a consideration of this scheme. It seems grossly unfair that specialists should have this preferential treatment over doctors who are desirous of entering general practice. It may be said that provision was made for them under the rehabilitation scheme, but this scheme was also available to specialists if they so desired. There must be many hundreds of doctors who would be only too glad of a subsidy of $£ 1,000$ for their first year in practice, and there seems no legitimate reason why they also should not be given a grant. It has been said that the specialist will suffer greatly owing to the difficulty in getting established before the coming of the National Health Service and that if something is not done he will be lost as a specialist. This is illogical, as presumably every doctor will be included in the Service, and if a doctor holds specialist qualifications I cannot believe that he will suffer by reason of having done other work in the meantime.

There are many doctors who were discharged from the Services on health grounds long before any provision for rehabilitation was made. Many of these must have suffered considerable har 4 ship, and I have personal knowledge of one case in which neither the B.M.A. nor any other body would give help even in the nature of a short-term loan where a doctor's health had been so impaired as to render him unable to insure his life.

This " spoon-feeding" is nothing short of deplorable, is playing into the hands of the Minister of Health, with whom we are still in disagreement, and, to those who accept it, nothing short of charity or unemployment pay-call it what you will. And all this at a time when there is plenty of work to be done. It is to be hoped that the young men now out of the Services will put their backs into the job, and even if the job is not quite what they would wish do it with a will and do away with any sense of weakness and dependency either on the State or their fellow men.-I am, etc.,

$$
\text { Sonning. }
$$$$
\text { J. J. DAvis }
$$

\section{Colonial Medical Service}

SIR,--Further to your correspondent "West Africa " (Dec. 21, 1946, p. 963), may I, after nearly four years' service on the "Coast," add a few points. Like "West Africa" in his early days I have been encouraging medical friends to consider the Colonial Service; but, with the new salary scale suggested by the Harragin Commission, I shall hold my tongue.

Even since 1943 the cost of living has risen considerably, and, as "West Africa" points out, will rise even further. For example, my cook gets and needs $75 \%$ more than when I took him over from another European who was leaving the country in 1943. Market prices are, theoretically, controlled in so far as fruit, fish, meat, and one or two other items are concerned, but a very skilful "fleece-the-white-man campaign" makes a mockery of the control. Household goods and basic foodstuffs imported from the United Kingdom are all more expensive than at home. Glassware, china, and other breakables suffer from constant packing and unpacking as well as from "boys." Linen and clothing generally suffer from the effects of a tropical climate. Replacements of all kinds, therefore, are heavier than would be the case in England. The necessity of providing a second home in England for a wife and children is an additional expense which must be considered in assessing the value of incomes applicable to tropical service.

To offer a man in these days $£ 680$ with the possibility of rising to $£ 1,200$ may attract unmarried adventurers for a short time, but will not retain the services of many men with a family or other commitments to consider. As a result of the Commission's report I will gain financially in the immediate future. In view, however, of the whole trend of policy in the past, as referred to by "West Africa" and one's older colleagues, I view my future in the Service with some apprehension. In consequence, much as I enjoy the type of life and the work and the friendly relationships existing in the department, I for one will leave the Service if the Commission's recommendations are adopted.-I am, etc.

"ThIRTY."

\section{The Unstable Adolescent Girl}

SIR,-In her letter (Jan. 4, p. 30) on the subject of the unstable adolescent girl Dr. Muriel Barton Hall gives I.Q.s as criteria for the diagnosis of degrees of mental deficiency, names mental defectives, moral defectives, and social defectives as separate entities, then criticizes the appendix to the report of the Committee on Psychiatry and the Law for offering no explanation as to which cases may be dealt with under the Mernal Deficiency Acts. Surely the answer is "mental defectives," and the definitions in the Act are quite clear. Mental deficiency is defined as " a condition of arrested or incomplete development of mind existing before the age of 18 years, whether arising from inherent causes or induced by diseases or injury." It should be noted that the deficiency is of mind, not of that particular aspect of mind which enables a patient to say why it is foolish for Bill Jones to put his trousers on over his head.

It follows that any type of mental inadequacy necessitating care and supervision can properly be dealt with under the M.D. Acts provided the inadequacy is due to inherent causes or was induced by disease or injury before the age of 18 years. Under the M.D. Acts machinery already exists for the care and treatment of. a large proportion of unstable adolescent girls, including those unnecessarily labelled psychopaths. While no one would wish to deny the value of mental tests when properly used. a little healthy debunking of the I.Q. may serve to clear the air and stimulate the utilization of the machinery already in existence.-I am, etc.,

St. Albans, Herts.

C. Guy Millman.

\section{Medico-Leg̊al}

\section{A STERILIZED HUSBAND}

Before the passage of Herbert's Act-The Matrimonial Causes Act, 1937-wilful refusal to consummate a marriage was not a ground for proceedings in either divorce or nullity. That Act, however, laid down that a marriage should be voidable on the ground that it had not been consummated owing to the wilful refusal of the respondent. In Cowen v. Cowen (1945) the Court of Appeal gave a wife a decree of nullity where her husband had either insisted on using a contraceptive or had practised coitus interruptus, so that he intentionally frustrated conception, one of the principal ends of marriage. The concept of wilful refusal has now been still further widened.

In $J . v . J .^{1}$ a husband, just before the marriage, had himself sterilized by vasectomy, telling the doctor who performed the operation that he desired it because there was insanity in the wife's family. Mr. Justice Jones found that this act amounted to wilful refusal to consummate the marriage. He rejected the wife's petition, however, on the ground of her acquiescence. Apparently the doctor who performed the operation had ins:sted that both parties should sign a statement declaring that they fully understood and realized that the operation, while likely to improve general conditions of health and function, produced total and irremediable sterilization. This statement was produced in court. The wife gave evidence that she had signed it on the husband's promise not to have the ope:ation until after they were married, but admitted that she knew of the operation before the marriage. The judge therefore he!d her to have acquiesced, and ruled that it would be inequitable and contrary to public policy to grant her a decree. 